\title{
ANALISIS SISTEM AKUNTANSI PEMBERIAN KREDIT AGUNAN RUMAH (KAR) PADA PT. BANK TABUNGAN NEGARA KANTOR CABANG MANADO
}

\author{
Yeremia Stevanus Elim Piay ${ }^{1}$, Inggriani Elim ${ }^{2}$, Robert Lambey ${ }^{3}$ \\ 1,2,3, Jurusan Akuntansi, Fakultas Ekonomi dan Bisnis, Universitas Sam Ratulangi, Jl. Kampus Bahu, \\ Manado, 95115, Indonesia \\ E-mail : evhan.piay@gmail.com
}

\begin{abstract}
Home mortgage loan is a credit facility from PT. Bank Tabungan Negara Branch Office Manado that can be used for various consumer needs by pledging the residence / apartment / shop / house. Implementation Granting of mortgage loans PT. Bank Tabungan Negara Branch Office Manado can be said easy and fast because it uses a good system. The credit accounting system is required to describe the system and procedures for crediting, and how the implementation of internal control over lending. The research method used in this thesis research is descriptive qualitative method that is by collecting data from research result then analyze it and draw conclusion from research, and research type used is descriptive skin. The results obtained that the accounting system of giving credit home mortgage at PT. Bank Tabungan Negara Branch Officer Manado runs well, and in accordance with the standard set, and is supported by the system E-loan, and Implementation of internal controls in the accounting system of home mortgage loans at PT. Bank Tabungan Negara Branch Officer Manado already meets the internal control elements of COSO well, as it is carried out in accordance with the standard operating policy guidelines of the procedures and policies of the directors.
\end{abstract}

Keywords : Credit, Accounting System, Analysis.

\section{PENDAHULUAN}

Era modernisasi yang sangat pesat perkembangannya menaikan standart kebutuhan manusia menuntut kita untuk memenuhinya. Kebutuhan manusia dapat dibagi menjadi kebutuhan Jasmani dan Rohani. Kebutuhan jasmani kita bisa mendapatkannya diberbagai tempat dengan mengeluarkan dana untuk memperolehnya. Kebutuhan jasmani yang beraneka ragam sesuai dengan hakekatnya yang selalu meningkat, sedangkan kemampuan untuk memenuhi kebutuhan sangat terbatas. Untuk memenuhi kebutuhan jasmani, kita membutuhkan adanya sumber-sumber dana, sumber-sumber dana tersebut didapatkan dari penghasilan dan pinjaman. Perusahaan yang bergerak di bidang keuangan memegang peranan penting dalam memenuhi kebutuhan dana. Hal ini disebabkan perusahaan yang bergerak dibidang keuangan ruang lingkup utama usahanya adalah menyediakan fasilitas penyediaan dana untuk pihak lain.

Bank BTN adalah sebuah perseroan terbatas yang bergerak dibidang penyediaan jasa perbankan. Bank BTN merupakan sebuah Badan Usaha Milik Negara (BUMN) yang dikenal oleh masyarakat sebagai bank yang mempunyai andil dalam melayani kredit perumahan. Salah satu fasilitas produk kredit yang diberikan oleh Bank BTN adalah Kredit Agunan Rumah (KAR). Melalui kredit ini Bank BTN menawarkan pinjaman untuk para calon debitur yang membutuhkan dana konsumtif dengan jumlah pinjaman tinggi. Kredit ini menggunakan syarat jaminan berupa sertifikat rumah, ruko, rukan, ataupun apartemen. Nilai kredit yang diberikan oleh bank BTN bebas, Bank BTN dapat mencairkan dana pinjaman kredit sesuai dengan nilai agunan yang dijaminkan, $70 \%$ dana pinjaman dapat cair dari nilai jumlah 
agunan. Alasan saya sebagai penulis memilih Kredit Agunan Rumah karena kredit tersebut banyak diminati oleh masyarakat dalam memenuhi kebutuhan konsumtif serta proses kreditnya cepat dan mudah.

Dalam hal ini sistem akuntansi pemberian kredit perlu di teliti untuk mengetahui bagaimana prosedur pemberian kredit, dokumen/bukti yang digunakan, fungsi yang terkait dan catatan akuntansi yang sudah berjalan dengan baik dan sesuai dengan prosedur, dan bagaimanakah pelaksanaan pengendalian internal dalam pemberian kredit ini (Budijayanto, 2012). Proses pemberian kredit harus sesuai dengan sistem pemberian kredit yang telah ditetapkan. Dengan adanya sistem yang jelas dalam pemberian kredit, maka dapat membantu pihak bank, terutama dalam penilaian terhadap calon debitur. Sistem pemberian kredit yang baik diharapkan dapat meningkatkan kinerja bank dan meningkatnya kepercayaan masyarakat (Dewi, 2012).

\section{TINJAUAN PUSTAKA}

\subsection{Sistem Akuntansi}

Akuntansi adalah sistem informasi yang mengukur aktivitas bisnis, memproses data menjadi laporan, dan mengkomunikasikan hasilnya kepada para pengambil keputusan (Horngren Harrison,2007:4). Sistem akuntansi adalah organisasi formulir, catatan dan laporan yang dikoordinasi sedemikian rupa untuk menghasilkan informasi keuangan yang diperlukan oleh manajemen untuk pengelolaan (Mulyadi 2016:3). sistem akuntansi sebagai alat yang digunakan untuk mengorganisir dan merangkum semua data yang menyangkut seluruh transaksi perusahaan untuk menghasilkan informasi yang diperlukan manajemen perusahaan dan pihak-pihak yang berkepentingan untuk mengawasi jalannya perusahaan dalam menentukan kebijakan-kebijakan atau tindakan-tindakan yang akan dilakukan dimasa yang akan datang.

\subsection{Sistem Akuntansi Pemberian Kredit}

Sistem akuntansi pemberian kredit adalah suatu sistem yang terdiri dari sekelompok unsur yang mempunyai keterkaitan satu dengan yang lainnya, sehingga sistem tersebut dapat digunakan untuk mengelola data yang berhubungan dengan usaha-usaha suatu perusahaan, menyebabkan terjadinya peristiwa pemberian kredit yang meliputi prosedur, dokumen, pencatatan dan bagian yang terkait dengan tujuan menghasilkan laporan yang dibutuhkan oleh manajemen dan pihak lain yang berkempentingan.

\subsubsection{Fungsi yang terkait dalam pemberian Kredit}

Dalam sistem akuntansi pemberian pinjaman ada beberapa fungsi yang terkait di dalamnya (Mulyadi, 2001: 487), yaitu:

1. Fungsi sekretariat.

2. Fungsi penagihan.

3. Fungsi kas.

4. Fungsi akuntansi.

5. Fungsi pemeriksaan intern.

Dapat disimpulkan bahwa fungsi-fungsi dalam pemberian kredit memiliki hubungan yang tidak bisa dilewati, karena setiap fungsi yang ada memiliki peranan penting dalam menentukan pemberian kredit dan pengembalian dana kredit. Dan melalui fungsi tersebut manajer bisa menilai kinerja setiap fungsi agar tidak terjadi perangkapan tugas dan tanggungjawab disetiap fungsi.

\subsubsection{Dokumen yang terkait dalam pemberian Kredit}

Dokumen merupakan secarik kertas yang digunakan untuk merekam terjadinya transaksi yang pertama kalinya sebagai dasar pencatatan dalam catatan (Mulyadi, 2001: 3). Dokumen yang digunakan dalam sistem pemberian kredit adalah:

1. Formulir permohonan kredit. 
2. Kwitansi.

3. Bukti pengeluaran kas.

4. Bukti penerimaan kas.

5. Kartu pinjaman.

Dokumen yang digunakan dalam pemberian kredit ini merupakan bukti yang kuat dalam merekam jejak nasabah pembayaran kredit, hingga pelunasan kredit. Dan juga menjadi dasar yang kuat bagi pihak nasabah dan bank jika terjadi komplain kredit yang bisa di pertanggungjawabkan oleh kedua pihak.

\subsubsection{Catatan Akuntansi yang terkait dalam pemberian kredit}

Catatan akuntansi yang digunakan dalam sistem akuntansi pemberian pinjaman merupakan catatan akuntansi yang digunakan untuk mencatat, mengklasifikasi dan meringkas data keuangan dan data lainnya (Mulyadi, 2001:4). Catatan yang digunakan dalam sistem pemberian kredit yang di kutip pada artikel Bizfluent (2018) adalah:

1. Buku Besar

2. Aplikasi Akuntansi Pinjaman.

3. Aplikasi Rekening Nasabah

4. Aplikasi Internet Banking

\subsection{Pengendalian Internal}

Dalam upaya mencapai tujuan utama, tiap perusahaan sudah sepatutnya memiliki suatu alat yang dapat dijadikan kontrol atas kinerja dan sistem yang berjalan didalamnya. Alat tersebut adalah pengendalian internal atau Internal Control. Pengendalian internal merupakan cara yang dilakukan manajemen perusahaan untuk mengurangi potensi timbulnya kecurangan yang mungkin terjadi dalam sistem yang ada di perusahaan.

\subsubsection{Tujuan Pengendalian Internal}

Menurut Arens dkk (2015 : 340), yang menjadi tujuan pengendalian internal pada sebuah perusahaan adalah sebagai berikut :

1. Reliability of Financial Reporting (Keandalan Laporan Keuangan)

2. Efficiency and Effectiveness of Operation (Operasi yang Efektif dan Efisien)

3. Compliance with Applicable Laws and Regulation (Ketaatan pada Hukum dan Peraturan)

\subsubsection{Unsur-Unsur Pengendalian Internal}

Komponen pengendalian internal menurut Commite of Sponsoring of Organization (COSO) dalam Internal Control - Integrated Framework (2013: 6-7), bahwa pengendalian internal memiliki lima komponen yang saling berhubungan, yaitu :

1. Lingkungan Pengendalian (Control Environment)

Lingkungan pengendalian didefinisikan sebagai seperangkat standar, proses, dan struktur yang memberikan dasar untuk melaksanakan pengendalian internal di seluruh organisasi.

2. Penilaian Resiko (Risk Assessment)

Penilaian risiko melibatkan proses yang dinamis dan interaktif untuk melaksanakan identifikasi dan penilai risiko dalam mencapai tujuan perusahaan.

3. Aktivitas Pengendalian (Control Activities)

Aktivitas pengendalian adalah tindakan-tindakan yang ditetapkan melalui kebijakan-kebijakan dan prosedurprosedur yang membantu memastikan bahwa arahan manajemen untuk mengurangi risiko terhadap pencapaian tujuan dilakukan.

4. Informasi dan Komunikasi (Information and Comunnication) bahwa informasi dan komunikasi sangat penting dalam melaksanakan tanggung jawab pengendalian internal untuk pencapaian tujuan-tujuannya dan. 
5. Aktivitas Pemantauan (Monitoring Activities)

Aktivitas pemantauan merupakan kegiatan evaluasi dengan beberapa bentuk apakah yang sifatnya berkelanjutan, terpisah ataupun kombinasi keduanya yang digunakan untuk untuk memastikan apakah masing-masing dari lima komponen pengendalian internal mempengaruhi prinsip-prinsip dalam setiap komponen, ada dan berfungsi.

\subsection{Kredit}

Menurut Kasmir (2014:85) dalam artian luas kredit diartikan sebagai kepercayaan. Begitu pula dalam bahasa latin kredit berarti "credere" artinya kepercayaan. Dalam konteks ini adanya kepercayaan dari pihak kreditur bahwa kredit yang disalurkan kepada debitur pasti akan dikembalikan beserta bunganya sesuai denga kesepakatan yang telah diperjanjikan sebelumnya. Sedangkan bagi si penerima kredit (debitur) merupakan penerimaan kepercayaan sehingga mempunyai kewajiban untuk membayar sesuai jangka waktu. kredit diberikan atas dasar kepercayaan kedua belah pihak, dimana pihak kreditur percaya bahwa debiturnya akan segera melunasi utangnya, dan pihak debitur percaya bahwa pihak kreditur akan menagih piutangnya pada saat jatuh tempo. selain itu, kredit juga mengandung unsur prestasi, dimana pihak peminjam/debitur memberikan prestasi kepada kreditur sebagai imbalan atas kredit yang telah diberikannya.

\subsection{Tahap-tahap pemberian kredit}

Dalam melaksanakan pemberian kredit, calon nasbah harus melalui beberapa tahapan proses untuk mendapatkan kredit yang diinginkan.

1. Permohonan Kredit

2. Analisa Kredit

3. Persetujuan dan Penolakan Kredit

4. Perjanjian Kredit

5. Pencairan Kredit

\subsection{Penelitian terdahulu}

Beberapa penelitian terdahulu yang penulis jadikan sebagai bahan pertimbangan dalam melakukan penelitian di Bank BTN. Penelitian yang dilakukan oleh Niken Devi Agustina tahun 2009, tentang Sistem Pemberian Kredit Kepemilikan Rumah (KPR) Subsidi, yang dilaksanakan pada PT. Bank Tabungan Negara (Persero) Cabang Surakarta, menyatakan bahwa Sistem dan Prosedur dalam pemberian KPR Subsidi sudah berjalan sesuai standart yang dilaksanakan oleh bank. Pada penelitian yang dilakukan oleh Aisa Fiana Sulmi tahun 2012, tentang Evaluasi Sistem Akuntansi Pemberian Kredit Agunan Rumah (KAR), yang dilaksanakan pada PT Bank Tabungan Negara (Persero) Tbk Kantor Cabang Pembantu Palur, menyatakan bahwa prosedur pemberian kredit yang diterapkan oleh bank BTN Cabang pembantu palur terdiri dari permohonan dan analisis kredit, dan prosedur pelunasan kredit secara menyeluruh telah sesuai standart ketentuan pemberian kredit yang telah ditetapkan oleh kantor pusat dan Bank Indonesia. Pada penelitian yang dilakukan oleh Rachmanika Hangga Dewi tahun 2012, tentang Analisis Sistem Pemberian Kredit Agunan Rumah (KAR), yang di laksanakan Pada Bank BTN Cabang Surakarta, menyatakan Sistem pemberian kredit agunan rumah dengan baik sesuai standar yang telah di tentukan oleh kantor pusat.

\section{METODE PENELITIAN}

\subsection{Jenis Penelitian}

Penelitian ini termasuk pada jenis penelitian kualitatif deskriptif. Indriantoro \& Supomo (2013: 26) mengutarakan penelitian deskriptif merupakan penelitian terhadap masalah-masalah berupa fakta-fakta saat ini dari suatu populasi. Deskriptif berhubungan dengan teknik pencatatan, pengorganisasian, dan peringkasan informasi dari data numerik atau data angka. Jenis penelitian dilakukan langsung ke sumber data, pengumpulan data 
menggunakan instrument penelitian, dan data yang terkumpul berupa visi dan misi perusahaan, struktur organisasi, dan informasi bagaimana prosedur yang di lakukan di PT. Bank Tabungan Negara Kantor Cabang Manado.

\subsection{Waktu dan Tempat Penelitian}

Penelitian dilakukan di PT. Bank Tabungan Negara Kantor Cabang Manado, yang merupakan perusahaan yang bergerak di bidang perbankan dalam hal ini menabung dan memberikan kredit. Dan berlokasi di Jl. Wolter Monginsidi No. 56, Bahu, Malalayang, Kota Manado, Sulawesi Utara. Waktu penelitian dimulai dari bulan Februari 2018 sampai Maret 2018.

\subsection{Metode Analisis}

Metode analisis yang digunakan dalam penulisan skripsi ini adalah metode deskriptif, yaitu untuk menggambarkan berbagai karakteristik data yang berasal dari suatu sampel (Sujarweni, 2014: 46). Untuk melakukan proses analisis penelitian, penulis mendeskripsikan dan menggambarkan data yang telah terkumpul melakukan analisis data, serta menerapkannya sedemikian rupa sehingga dapat ditarik kesimpulan untuk menjawab permasalahan yang ada.

\section{HASIL ANALISIS DAN PEMBAHASAN}

\subsection{Hasil analisis}

\subsubsection{Fungsi yang terkait dalam pemberian Kredit Agunan Rumah (KAR)}

Dalam pelaksanaan sistem akuntansi pemberian kredit agunan rumah (KAR) pada PT. Bank Tabungan Negara Kantor Cabang Manado terdapat bagian yang terkait di dalamnya:

1. Loan Service

2. Data Entry Operational

3. Consumer Loan Analyst

4. Loan Administration Staff

5. Loan Administration Head

6. Branch Manager

7. Deputi Branch Manager Bussiness

8. Mortgage Consumer Lending Unit Head

9. Loan Document

10. Transaction Processing

\subsubsection{Dokumen yang terkait dalam pemberian Kredit Agunan Rumah (KAR)}

Dokumen yang digunakan dalam sistem akuntansi pemberian kredit agunan rumah (KAR) pada PT. Bank Tabungan Negara Kantor Cabang Manado adalah

1. Dokumen Pendukung

a. Formulir Aplikasi Consumer Loan

b. Surat Kuasa Pemotongan Gaji/Pensiunan

c. Fotocopy KTP, Kartu Keluarga, Surat Nikah/Cerai

d. Fotocopy NPWP

e. Asli slip gaji terakhir atau Surat Keterangan Penghasilan

f. Fotocopy SK Pengangkatan Pegawai Tetap

g. Fotocopy Tabungan/Giro di Bank BTN/Bank lain min. 3 (tiga) bulan terakhir

h. Fotocopy SPT Tahunan

i. Fotocopy Akta Pendirian Perusahaan berikut perubahannya Izin Usaha, NPWP, SIUP, TDP, SITU \& Laporan Keuangan/usaha Terakhir

j. Fotocopy Ijin-ijin praktek

k. Fotocopy SHM/SHGB/ dan IMB

1. Foto rumah $\&$ denah lokasi rumah yang akan dibeli/diagunkan 
m. Denah lokasi tempat kerja/tempat usaha

2. Dokumen Proses

a. Surat Permohonan Kredit (SPK)

b. Formulir BI Checking (FBI)

c. Laporan Penilaian Agunan (LPA)

d. Laporan Hasil Analisa Kredit (LHAK)

e. Surat Penolakan Permohonan Kredit (SP)

f. Surat Penegasan Persetujuan Penyediaan Kredit (SP3K)

g. Surat Pernyataan dan Kuasa Pemindahbukuan (SPKPB)

h. Perjanjian Kredit (PK)

i. Surat Persetujuan Debitur (SPD)

3. Dokumen Agunan

a. Sertifikat Hak Milik (SHM) / Surat Hak Guna Bangunan (SHGB)

b. Izin Mendirikan Bangunan (IMB)

4.1.3 Catatan Akuntansi yang terkait dalam pemberian Kredit Agunan Rumah (KAR)

Catatan akuntansi yang digunakan dalam sistem akuntansi pemberian kredit agunan rumah (KAR) adalah sebagai berikut:

1. Buku Register

2. Sistem Layanan Informasi Keuangan (SLIK)

3. Sistem E-loan

4. Sylvester Integrated Banking System (SIBS)

\subsection{Pembahasan}

\subsubsection{Analisis Sistem Akuntansi Pemberian Kredit Agunan Rumah (KAR)}

Dalam melaksanakan sistem akuntansi pemberian kredit agunan rumah, PT Bank Tabungan Negara Kantor Cabang Manado mengunakan sistem E-loan. Sistem E-loan merekap data kredit mulai dari pengajuan kredit, analisa kredit, membuat keputusan kredit, hingga ke pencairan kredit. Untuk mengakses sistem ini dapat dilakukan melalui internet explore dan mozila firefox, tetapi PT Bank Tabungan Negara Kantor Cabang Manado mengaksesnya melalui internet explore, dengan pertimbangan untuk lebih mudah untuk menggunakannya. Sistem E-loan ini diawasi langsung oleh provider yang berada di kantor pusat Bank BTN, sehingga jalannya proses pemberian dapat dipantau dari kantor pusat dan semua berkas yang di masukan ke dalam sistem dan di cadangkan oleh provider kantor pusat. Tetapi tidak menutup kemungkinan untuk penyimpanan berkas nasabah pada sistem ini akan bertambah, melihat banyaknya nasabah yang mengambil kredit di Bank BTN khususnya kredit agunan rumah, sehingga perlu memperbesar kapasitas penyimpanan pada sistem ini. Untuk keamanan dari sistem $E$ loan PT. Bank Tabungan Negara Kantor Cabang Manado melakukan tindakan dengan Membarui password pengguna sistem setiap bulan, memiliki kerjasama dengan vendor jaringan dan aplikasi, dan diawasi langsung oleh provider dari kantor pusat.

Dalam melaksanakan proses pemberian kredit melalui sistem E-loan sangat efektif dan efisien. Efektif, dalam melaksanakannya tidak perlu menunggu waktu yang lama untuk proses pemberian kredit karena semua bagian yang terkait pemberian kredit agunan rumah bisa mengaksesnya. Efisien, dalam pelaksanaannya tidak memerlukan banyak kertas untuk melaksanakan proses pemberian kredit, karena semua berkas, hasil penilaian, dan keputusan dapat di input pada sistem ini.

Sistem E-loan dan sistem SILK IDeb merupakan sistem yang diperlukan dalam pemberian kredit, sistem E-loan sebagai tempat untuk memproses pemberian kredit melalui data dan berbagai analisa dan keputusan, dan sistem SILK IDeb merupakan penyedia data informasi keuangan debitur. Untuk meningkatkan performa layanan dari 
sistem E-loan dan keakuratan data debitur secara lansung, sebaiknya sistem E-loan dapat terhubung dengan sistem SILK IDeb, dalam hal ini sistem E-loan bisa menganalisa informasi debitur dan melakukan penilaian kualitas/jumlah tunggakan dalam pemberian kredit yang dilakukan debitur pada lembaga keuangan lain, dan data diperoleh dapat dipercaya.

Berdasarkan data yang di dapat pada saat penelitian tentang Kredit Agunan Rumah (KAR) pada PT. Bank Tabungan Negara Kantor Cabang Manado. Data tersebut diolah untuk membahas tujuan dari penelitian yaitu untuk mengetahui bagaimana Sistem Akuntansi Pemberian Kredit Agunan Rumah (KAR) Pada PT Bank Tabungan Negara Kantor Cabang Manado. Sistem Akuntansi Pemberian Kredit yang dilaksanakan PT. Bank Tabungan Negara Kantor Cabang Manado meliputi fungsi yang terkait, dokumen yang digunakan, catatan akuntansi yang digunakan, dan prosedur yang digunakan.

1. Fungsi yang terkait

Dalam pelaksanaan proses pemberian kredit harus melewati beberapa bagian yang terpisah menurut struktur organisasi agar bisa merealisasikan kredit. Tetapi perlu dievaluasi kembali apakah bagian Loan Administration Staff yang melaksanakan survey lapangan. Sebaiknya untuk tugas pelaksanaan survey lapangan di lakukan oleh bagian Consumer Loan Analyst karena bagian ini yang lebih tepat untuk melaksanakan survey lapangan. Dengan demikian, bagian Consumer Loan Analyst bisa menilai langsung bagaimana keadan dari agunan yang di jaminkan untuk dinilai, agar tidak terjadi resiko agunan yang dijaminkan. Dan juga perlu ditambahkan kedalam struktur organisasi secara terbuka untuk bagian Data Entry Operational karena bagian ini merupakan bagian yang memiliki peranan penting dalam proses pemberian kredit.

2. Dokumen yang digunakan

Dalam pelaksanaanya semua dokumen bernomor urut cetak sehingga dapat memudahkan pengarsipan dokumen. Dan juga dokumen ini tersimpan pada sistem $E$ loan yang mudah diakses tanpa harus melihatnya di bagian Loan Document.

3. Catatan Akuntansi yang digunakan

Catatan akuntansi yang digunakan dalam sistem akuntansi pemberian kredit agunan rumah (KAR) banyak menggunakan sistem, seperti mengecek data BI Checking di sistem IDeb SLIK, menginput data permohonan, hasil analisa, persetujuan hingga pencairan melalui sistem E-loan dan mengecek rekening debitur pada sistem SIBS. Pencatatan Register pada buku register hanya mencatat rek debitur, nilai Plafond Kredit, dan Beberapa data dari BI Checking.

4. Prosedur Pemberian kredit

a. Pengajuan dan Permohonan Kredit Agunan Rumah (KAR)

Proses pengajuan dan permohonan kredit dilaksanakan pada bagian Loan Service. Pada pelaksanaannya Loan Service melakukan wawancara kepada debitur, mengisi buku register, mengecek data BI Checking di IDeb SILK, dan menginput data pribadi calon debitur pada sistem E-loan, dan bagian Data Entry Operational melengkapi data calon debitur pada E-loan. Dari proses yang dilaksanakan ini, untuk menginput data nasabah sebaiknya di lakukan oleh satu bagian agat bisa lebih efektif lagi.

b. Analisa Kredit Agunan Rumah (KAR)

Dalam melaksanakan analisa kredit, bagian Loan Analyst Service hanya berpedoman pada prinsip 3C yaitu Capacity, Character, dan Collacteral untuk melihat prinsip Capital dan Condition dapat tercermin pada Capacity. Sebaiknya bagian Consumer Loan Analyst menganalisanya secara terpisah karena bisa saja 
terjadi kesengajaan tidak membayar angsuran walaupun memiliki dana untuk membayar.

c. Keputusan Persetujuan dan Penolakan Kredit Agunan Rumah (KAR)

Keputusan kredit dilakukan oleh bagian pemutus kredit sesuai nilai Plafond Kredit, yaitu untuk nilai Plafond Kredit 100 juta - 300 juta dilakukan oleh Mortgage Consumer Loan Unit, untuk nilai Plafond Kredit > 300 juta - 1 Milyar dilakukan oleh Deputi Branch Manager, untuk nilai Plafond Kredit > 1 Milyar dilakukan oleh Branch Manager dan Credit Risk. Proses ini sesuai dengan tingkatan pengambilan keputusan kredit, namun untuk nilai Plafond Kredit dibawah 1 Milyar perlu dilakukan penilaian resiko kredit oleh Credit Risk.

d. Realisasi Kredit Agunan Rumah (KAR)

Proses realisasi kredit ini dilakukan dimana telah terjadi persetujuan kredit oleh bagian pemutus kredit. Dalam pelaksanaannya debitur menyerahkan dokumen agunan kepada Loan Service dan menandatangani perjanjian kredit, Loan Service meminta legalitas atas dokumen agunan kepada notaris serta menandatangani perjanjian kredit tersebut, dan Loan Service dan bagian pemutus kredit menandatangani dokumen perjanjian kredit. Dalam hal ini terjadi perikatan kredit antara pihak debitur dan pihak bank yang sah secara hukum. Untuk pencairannya debitur harus menyediakan dana di rekening tabungan untuk membayar biaya provisi dan premi asuransi.

Dari data hasil penelitian PT. Bank Tabungan Negara Kantor Cabang Manado telah memiliki 5 komponen pokok pengendalian internal berdasarkan prinsip COSO, yang dapat di lihat pada komponen-komponen sebagai berikut.

1. Lingkungan Pengendalian (Control Environment)

Dalam melakukan pemberian kredit, manajemen PT. Bank Tabungan Negara Kantor Cabang Manado sudah dibekali dengan prinsip Know Your Employe prinsip ini juga digunakan dalam memberikan kredit dimana manajemen harus mengenali dan mengetahui informasi tentang calon debitur sebelum memberikan kredit yang dibuktikan dengan melaksanakan wawancara, melihat dokumen pendukung kredit, dan melihat data rekaman pembiayaan debitur pada SILK IDeb. Untuk pembagian tugas dalam pemberian kredit telah dilaksanakan dengan baik sesuai struktur organisasi dan tugas tanggungjawab.

2. Penilaian Resiko (Risk Assessment)

Dalam melaksanakan pemberian kredit, proses penilaian resiko yang dilakukan PT. Bank Tabungan Negara Kantor Cabang Manado yaitu dengan menggunakan sistem four eyes dimana penilaian dan pemutus kredit dilakukan oleh bagian pemutus kredit (Branch Manager) dan bagian Credit Risk untuk kredit yang jumlahnya di atas satu Milyar sedangkan untuk kredit dibawah satu milyar penilain kredit dilaksanakan oleh bagian Consumer Loan Analyst dan pemutus kredit dilakukan oleh bagian pemutus kredit (Mortgage Consumer Lending Unit Head /Deputi Branch Manager) sesuai tingkatan Plafond Kredit. Untuk mencegah terjadi kecurangan dalam pemberian kredit selain menggunakan prinsip four eyes dilakukan juga refresh job desk yang dilakukan agar tidak terjadi penyalahgunaan wewenang dalam pemberian kredit.

3. Aktivitas Pengendalian (Control Activities)

Dalam melaksanakan pemberian kredit, aktivitas pengendalian internal yang dilakukan PT. Bank Tabungan Negara Kantor Cabang Manado dapat dilihat dari pengotorisasian yang di lakukan jelas, bernomor urut dan tanggal pada dokumen yang terkait pemberian kredit dan pemisahan fungsi yang cukup baik. Kebijakan-kebijakan dalam pemberian kredit yang dilaksanakan sudah sesuai dengan petunjuk manajemen dan batasan-batasan tertentu sesuai tugas dan tanggung jawab setiap bagian dalam 
pemberian kredit, dibuktikan dengan tingkatan pemutus kredit sesuai dengan plafond kredit, dan bagian Credit Risk yang mengambil kebijakan berdasarkan penilaian resiko kredit, sesuai standard operasional prosedur dan surat edaran direksi.

4. Informasi dan Komunikasi (Information and Communication)

Dalam melaksanakan pemberian kredit, PT. Bank Tabungan Negara Kantor Cabang Manado memperoleh informasi dari sistem layanan informasi keuangan dari OJK, dimana dapat dilihat aktivitas pinjaman yang dilakukan debitur pada lembaga keuangan lainnya. Dan komunikasi yang terjadi dalam pemberian kredit pihak PT. Bank Tabungan Negara Kantor Cabang Manado memberitahu debitur tentang persyaratan dalam pemberian kredit yang harus di penuhi, dan menghubungi notaris untuk meminta legalitas hukum dalam melaksanakan perjanjian kredit sebagai salah satu prosedur pemberian kredit.

5. Aktivitas Pemantauan (Monitoring Activities)

Dalam melaksanakan pemberian kredit, PT. Bank Tabungan Negara Kantor Cabang Manado memantau aktivitas kredit melalui dua sistem yaitu sistem E-loan dan SIBS. Pada sistem E-loan bisa dilihat bagaimana jalannya prosedur pemberian kredit mulai dari permohonan kredit hingga realisasi kredit yang bisa di pantau oleh bagian-bagian yang terkait pemberian kredit. Pada sistem SIBS bisa dilihat perkembangan bagaimana pengunaan dana kredit dan pelunasan kredit yang dilakukan debitur. Sehingga dapat mengetahui jalannya prosedur pemberian kredit dengan baik serta mencegah penyalahgunaan wewenang, dan PT. Bank Tabungan Negara Kantor Cabang Manado dapat mengindentifikasi resiko kerugian pemberian kredit.

\section{KESIMPULAN DAN SARAN}

\subsection{Kesimpulan}

Berdasarkan hasil penelitian dan pembahasan yang telah di kemukakan sebelumnya maka dapat diambil kesimpulan bahwa PT. Bank Tabungan Negara Kantor Cabang Manado telah melaksanakan sistem akuntansi pemberian kredit agunan rumah (KAR) dengan baik dan memenuhi unsur pengendalian internal dari COSO, dan sesuai dengan standart yang ditetapkan, serta di dukung dengan sistem E-loan yang dapat memberikan kemudahan dalam proses pemberian kredit dan pengambilan keputusan kredit, yang lebif efektif dan efisien dari sistem pemberian kredit yang biasa. Untuk pelaksanaan proses pemberian kredit dilakukan secara terpisah pada setiap bagian, di dukung dengan dokumen dan catatan akuntansi yang baik sehingga pemberian kredit yang dilakukan sudah maksimal. Pelaksanaan tahap-tahap pada sistem pemberian kredit yaitu tahap permohonan dan pengajuan, tahap analisa kredit, tahap pengambilan keputusan, dan tahap realisasi kredit yang teratur dalam pelaksanaannya. Pelaksanaan pengendalian internal pada sistem akuntansi pemberian kredit agunan rumah (KAR) pada PT. Bank Tabungan Negara Kantor Cabang Manado sudah cukup baik karena dilaksanakan sesuai dengan pedoman standart operasional prosedur dan kebijakan direksi. Serta didukung dengan prinsip (Know Your Employee dan Four Eyes) yang sangat kompeten yang bisa membantu dalam meminimalisir resiko kredit, serta dengan sistem (SILK IDeb dan SIBS) yang membantu untuk memberikan informasi yang relevan dalam melakukan pemantauan pengendalian internal..

\subsection{Saran}

Sesuai dengan hasil penelitian dan analisis yang dilakukan sebelumnya, maka agar dapat lebih meningkatkan kinerja sistem akuntansi pemberian kredit agunan rumah pada PT. Bank Tabungan Negara Kantor Cabang Manado.

1. Untuk sistem E-loan perlu adanya penambahan kapasitas penyimpanan data nasabah pada sistem ini, dan untuk meningkatkan performa layanan sistem E-loan dan 
informasi data debitur yang akurat perlu adanya akses sistem SILK IDeb pada sistem E-loan.

2. Untuk proses pelaksanaan peninjauan lapangan, sebaiknya dilakukan oleh bagian Consumer Loan Analyst karena lebih tepat. Dan bagian Consumer Loan Analyst bisa menilai langsung bagaimana keadaan dari agunan yang di jaminkan untuk dinilai, agar tidak terjadi resiko agunan yang dijaminkan, untuk melaksanakan pengisian data calon debitur alangkah baiknya di lakukan satu bagian saja antara Loan Service dan Data Entry Operational. Dan untuk bagian Data Entry Operational perlu ditambahkan ke dalam struktur organisasi secara terbuka karena memiliki peranan penting dalam pemberian kredit.

3. Untuk melaksanakan analisa kredit berdasarkan teori, sebaiknya bagian Loan Analyst Service menganalisanya secara terpisah terhadap prinsip 5C yaitu Character, Capacity, Collacteral, Capital, dan Condition, karena bisa saja terjadi kesengajaan tidak membayar angsuran walaupun memiliki dana untuk membayar.

4. Untuk menganalisa resiko kredit yang dilakukan oleh bagian Credit Risk sebaiknya dilakukan pada semua tingkatan nilai plafond kredit bukan hanya pada tingkatan nilai plafond kredit yang nilainya diatas satu milyar, agar bisa lebih meminimalisir resiko kerugian kredit pada tingkatan nilai plafond kredit yang lebih rendah.

\section{DAFTAR PUSTAKA}

Arens A. A, R. J. Elder., dan M. S. Beasley. 2015. Auditing and Assurance Service an Integrated Approach. 15th ed. Pearson International Edition. New Jersey

Budijayanto E. D. 2012. Sistem Akuntansi Pemberian Kredit Pada PD. BPR BKK Ungaran Kabupaten Semarang. Tesis. Universitas Negeri Semarang. Semarang.

Charles T. H. dan W. T. Harrison. 2007. Akuntansi jilid Satu. Edisi Tujuh. Jakarta: Penerbit Erlangga.

Committee of Sponsoring Organizations of the Treadway Commission (COSO), 2013, Internal Control - Integrated Framework: Executive Summary, Durham, North Carolina.

Dewi. R. H. 2012. Analisis Sistem Pemberian Kredit Agunan Rumah (KAR) Pada Bank BTN Cabang Surakarta. Tugas Akhir Program Diploma III. Universitas Sebelas Maret.

Kasmir. 2014. Bank dan Lembaga Keuangan Lainnya. Edisi Revisi 2014, PT. Raja Grafindo Persada. Jakarta.

Mulyadi, 2001, Sistem Informasi Akuntansi. Salemba Empat. Jakarta. . 2016. Sistem Akuntansi. Edisi Keempat. Salemba Empat. Jakarta. 